These uncertainties concerning power line distance lead to a very rough estimate of the child exposure to the MF produced by a power line (which is the subject of the study), as MF decreases in inverse proportion to the square of the distance. Moreover, this estimate takes into account neither the effective residence duration in the vicinity of the power lines nor other sources of exposure - at home or in other places such as at nursery or at school - nor other potential confounding factors.

\section{REFERENCES}

Draper G, Vincent T, Kroll M, Swanson J (2005) Childhood cancer in relation to distance from high voltage power lines in England and Wales: a case-control study. BMJ 330: 1290.
Maslanyj M, Simpson J, Roman E, Schüz J (2009) Power frequency magnetic fields and risk of childhood leukemia: misclassification of exposure from the use of the 'distance from power line' exposure surrogate. Bioelectromagnetics 30: 183-188.

Sermage-Faure C, Demoury C, Rudant J, Goujon-Bellec S, Guyot-Goubin A, Deschamps F, Hemon D, Clavel J (2013) Childhood leukaemia close to high-voltage power lines-the Geocap study, 2002-2007. Br J Cancer 108: 1899-1906.

Sienkiewicz Z, Schüz J, Poulsen AH, Cardis E (2010) Risk analysis of human exposure to electromagnetic fields. European Health Risk Assessment Network on Electromagnetic Fields Exposure (EFHRAN). Available from http://efhran.polimi.it/docs/EFHRAN_D2_final.pdf.

(c) (1) (2) This work is licensed under the Creative Commons cc) Attribution-NonCommercial-Share Alike 3.0 Unported License. To view a copy of this license, visit http://creativecommons. org/licenses/by-nc-sa/3.0/

\title{
Reply: Comment on 'Childhood leukaemia close to high-voltage power lines - the Geocap study, 2002-2007' - Is proximity an appropriate MF exposure surrogate?
}

J Clavel ${ }^{\star, 1,2,3}$, C Sermage-Faure ${ }^{1,2}$, C Demoury ${ }^{1,2}$, J Rudant ${ }^{1,2,3}$, S Goujon-Bellec ${ }^{1,2,3}$, A Guyot-Goubin ${ }^{1,2,3}$, F Deschamps ${ }^{4}$ and D Hémon ${ }^{1,2}$

${ }^{1}$ Inserm U1018, Center for Research in Epidemiology and Population Health (CESP) Equipe 6, Environmental Epidemiology of Cancer Team, 16 Av. Paul Vaillant-Couturier, F-94807 Villejuif, France; '2University Paris-Sud, UMRS 1018, F-94807 Villejuif, France; ${ }^{3}$ French National Registry of Childhood Hematological Malignancies (NRCH), Villejuif, France and ${ }^{4}$ Réseau de Transport d'Electricité (RTE), Coeur Défense, 110 Esplanade du Général de Gaulle, 92030 La Defense, France

Sir,

We would like to thank Bonnet-Belfais et al (2013) for their interest in our work. We fully agree that addressing the possible link between childhood acute leukaemia (AL) and exposure to magnetic fields (MF) is a difficult task. In our article, we analysed the relationship between $\mathrm{AL}$ and close proximity to high-voltage overhead lines (HVOL), not exposure to MF. The methods, results, discussion and conclusions did not deviate from that objective. We did not use the distance from HVOL as a proxy of ELF-MF exposure, but as a marker of a subpopulation of French children who, on average, are expected to be exposed more often to higher levels of ELF-MF because they live close to HVOL.

Bonnet-Belfais et al (2013) considered the coordinates based on photographic views as an accurate gold standard and contrasted them with the coordinates obtained by the main geocoding

${ }^{*}$ Correspondence: Dr J Clavel; E-mail: Jacqueline.Clavel@inserm.fr

Published online 15 August 2013

(C) 2013 Cancer Research UK. All rights reserved 0007-0920/13

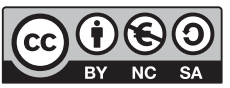

BPEN 0 
process, which they considered to be automatic and inaccurate. Actually, both geocoding processes are subject to uncertainties and inaccuracies. The coordinates based on photographs may also be inaccurate and may even overestimate the distance, for instance, by locating dwellings in the middle of the building instead of by the roadside. Moreover, the main geocoding was also completed manually, particularly for rural areas, and was not merely automatic. While the main geocoding was accessible for the entire sample, the photographic views were available for a subset of addresses, most often in urban areas, and unequally for the cases and controls. Overall, the sensitivity analyses did not call into question the conclusions of the main analyses and for that reason were not reported in the abstract.

Bonnet-Belfais et al (2013) listed some differences between the main analyses and the sensitivity analyses, and mistakenly interpreted them as if the photographs yielded the true coordinates. We performed sensitivity analyses to assess the robustness of the results under different uncertainty scenarios, and therefore restricted the analyses to the addresses the most precisely located by the main geocoding process or to the addresses geocoded with a photographic view (Table 5). We also used other limits of distance $(30,40,60$ and $70 \mathrm{~m})$ from the lines. All of the sensitivity analysis results supported the main results, sometimes smoothing and sometimes strengthening them. It is also to be noted that our study did not include any assessment of MF exposure that could be used to refute or confirm 'distance as an inappropriate MF exposure surrogate'. Bonnet-Belfais et al (2013) express their belief that 'personal exposure (is) the only one (MF exposure surrogate) relevant in terms of public health.' This belief is debatable in the absence of any established causal link with MF. It is noteworthy that measurements of personal exposures are difficult to standardise and subject to selection and measurement errors, particularly in the context of case-control studies, in which the exposures are usually available for a limited timeframe, and for a selected and sometime small fraction of the study samples. This may weaken the relevance of those exposures in terms of public health.

The next stages of our study will include a case-by-case model-based assessment of exposure to ELF-MF. The assessment should enable further elucidation of the exposures or biases underlying our findings and the other environmental factors that may be associated or co-associated with power lines and/or ELF-MF exposure.

\section{REFERENCE}

Bonnet-Belfais M, Lambrozo J, Aurengo A (2013) Comment on 'Childhood leukemia close to high-voltage power lines - the Geocap study, 2002-2007' - Is proximity an appropriate MF exposure surrogate? Br J Cancer 109(5): $1382-1383$.

cc)(i)(2) This work is licensed under the Creative Commons Attribution-NonCommercial-Share Alike 3.0 Unported License. To view a copy of this license, visit http://creativecommons. org/licenses/by-nc-sa/3.0/

\title{
Comment on 'Childhood leukaemia close to high-voltage power lines - the Geocap study, 2002-2007' - Odds ratio and confidence interval
}

\author{
M T Magaña Torres ${ }^{1}$ and J R Gonzalez Garcia ${ }^{\star, 1}$ \\ ${ }^{1}$ Division de Genetica, Centro de Investigacion Biomedica de Occidente, Instituto Mexicano del Seguro Social, \\ Sierra Mojada \#800, Colonia Independencia, Guadalajara, Jalisco CP 44340, Mexico
}

Sir,

The precision of the odds ratio (OR) test is estimated by the $95 \%$ confidence interval, which is interpreted as significant when its values do not overlap the 1.0 null value (Szumilas, 2010). In this context, some sentences of the results section in the paper by Sermage-Faure et al (2013) are unwarranted. These sentences are 'an association was evidenced for children who lived within $50 \mathrm{~m}$ of a VHV-HVOL $(\mathrm{OR}=1.7(0.9-3.6))$ '; 'The results for ALL were 